\title{
Anti-Inflammatory, Analgesic, and Antipyretic Activities of the Ethanol Extract of Piper interruptum Opiz. and Piper chaba Linn.
}

\author{
Seewaboon Sireeratawong, ${ }^{1}$ Arunporn Itharat, ${ }^{2}$ Nusiri Lerdvuthisopon, ${ }^{3}$ \\ Pritsana Piyabhan, ${ }^{4}$ Parirat Khonsung, ${ }^{5}$ Supot Boonraeng, ${ }^{6}$ and Kanjana Jaijoy ${ }^{5}$ \\ ${ }^{1}$ Division of Pharmacology, Department of Preclinical Science, Faculty of Medicine, Thammasat University, \\ Pathumthani 12120, Thailand \\ ${ }^{2}$ Department of Applied Thai Traditional Medicine, Faculty of Medicine, Thammasat University, Rungsit Campus, \\ Pathumthani 12120, Thailand \\ ${ }^{3}$ Division of Biochemistry, Department of Preclinical Science, Faculty of Medicine, Thammasat University, \\ Pathumthani 12120, Thailand \\ ${ }^{4}$ Division of Physiology, Department of Preclinical Science, Faculty of Medicine, Thammasat University, Pathumthani 12120, Thailand \\ ${ }^{5}$ Department of Pharmacology, Faculty of Medicine, Chiang Mai University, Chiang Mai 50200, Thailand \\ ${ }^{6}$ Department of Animal Science, Faculty of Agricultural Technology, Chiang Mai Rajabhat University, Chiang Mai 50300, Thailand
}

Correspondence should be addressed to Seewaboon Sireeratawong, seewaboon@gmail.com

Received 20 December 2011; Accepted 11 January 2012

Academic Editors: R. Fantozzi and M. van den Buuse

Copyright ( $(2012$ Seewaboon Sireeratawong et al. This is an open access article distributed under the Creative Commons Attribution License, which permits unrestricted use, distribution, and reproduction in any medium, provided the original work is properly cited.

\begin{abstract}
Piper interruptum Opiz. and Piper chaba Linn. are herbaceous plants in the Piperaceae family. The ethanol extract of $P$. interruptum and $P$. chaba inhibited ethyl phenylpropiolate-induced ear edema and carrageenan-induced hind paw edema in rats. Both extracts reduced transudative and granuloma weights as well as body weight gain and thymus weight of the chronic inflammatory model using cotton pellet-induced granuloma formation in rats. Moreover, both extracts exhibited analgesic activity on both early phase and late phase of formalin test in mice and also showed antipyretic activity on yeast-induced hyperthermia in rats.
\end{abstract}

\section{Introduction}

The Piperaceae is a huge family of plants, which has been extensively used for traditional medicine. In Thailand, $P$. interruptum or P. ribesoides Wall., called Sa-kan, is commonly found in the northern and northeastern parts. The stem has long been used as carminative, antiflatulent, and tonic element [1]. There are few reports on pharmacological activity of this plant. The ethanol extract of stem showed larvicidal effect [2] and the methanol extract exhibited inhibitory activity on acetylcholinesterase enzyme [3].

P. chaba or P. longum Linn. or long pepper has various Thai local names such as Di-pli, Prik-hang, Diplichueak. In Thai traditional systems of medicine, the dried mature unripe fruits of this plant find wide application as carminative, element tonic, antidiarrheal, expectorant and oxytocic for postlabor [4]. The fruit extract of $P$. chaba has been shown to exhibit various activities including antiinflammation [5-7], hepatoprotection [8], cytotoxicity and antitumor [9], chemoprevention [10], antiangiogenesis [11], immunomodulation [12], and adipogenesis [13].

The purpose of this study was to evaluate anti-inflammatory, analgesic, and antipyretic activities of ethanol extract from stem of $P$. interruptum and fruit of $P$. chaba in animal models.

\section{Materials and Methods}

2.1. Plant Materials. Stem of P. interruptum (PI) was collected from Phupan, Sakhonnakhon and fruit of P. chaba 
(PC) from Khaosaming, Chanthaburi, Thailand. The certifications of plant materials were carried out at the herbarium of Department of Forestry, Bangkok, whereas the herbarium vouchers have been kept at the herbarium of Southern Center of Thai Medicinal plant at Faculty of Pharmaceutical Science, Prince of Songkhla University, Songkhla, Thailand. SKP 146160901 and SKP 146160301 are voucher numbers of $P$. interruptum and P. chaba, respectively.

2.2. Preparation of Plant Extracts. All plant materials were cleansed using water to reduce microbial load. Next, they were cut into small pieces and dried at $50^{\circ} \mathrm{C}$, powdered, and extracted following a similar procedure of Thai traditional practice. Dried ground plant material $(1 \mathrm{Kg}$ ) was macerated with $95 \%$ ethanol for 3 days, filtered and concentrated to dryness under pressure. The maceration was repeated twice and then dried by evaporator. The percentage yields of PI and PC extracts were calculated as 2.47 and 10.89 , respectively.

2.3. Experimental Animals. Male Sprague-Dawley rats weighing $40-60,100-120$, and $200-250 \mathrm{~g}$ as well as male ICR mice weighting 30-40 g were obtained from National Laboratory Animal Center, Nakorn Pathom, Thailand. Six animals were randomly assigned to each group of control and treatment. They were kept in a room maintained under environmental conditions of $25 \pm 1^{\circ} \mathrm{C}$ and $12 \mathrm{~h}$ dark-light cycle. The animals had free access to water and food. Rats were kept in the experimental facility for 1 week to allow them to be acclimated prior to dosing. The Animal Ethics Committee of Faculty of Medicine, Thammasat University, Pathumthani, Thailand, approved all experimental protocols (no. 0002/2008). After the experiments, all animals were sacrificed.

\subsection{Anti-Inflammatory Study}

2.4.1. Ethyl-Phenylpropiolate-(EPP-) Induced Ear Edema in Rats [14]. Male rats weighing 40-60 g were used for topical application of EPP $1 \mathrm{mg} / 20 \mu \mathrm{L} /$ ear to induce edema on the inner and outer surface of both ears. The test substances were applied in the same manner in a volume of $20 \mu \mathrm{L}$ prior to applying the irritants. Control group received acetone ( $20 \mu \mathrm{L} /$ ear), and the reference group received $1 \mathrm{mg} / 20 \mu \mathrm{L} /$ ear of phenylbutazone in acetone. The test group received PI or PC extract at the dose of $1 \mathrm{mg} / 20 \mu \mathrm{L} /$ ear. The thickness of each ear was measured with a digital vernier caliper before and at 15,30,60, and 120 min after edema induction.

2.4.2. Carrageenan-Induced Paw Edema in Rats [15]. Male rats weighing 100-120 g were divided into five groups of six rats each. The test groups were received PI or PC extract (300, $600,1,200 \mathrm{mg} / \mathrm{kg})$, aspirin $(300 \mathrm{mg} / \mathrm{kg})$, and $5 \%$ Tween 80 (control). The test substances were orally administered 1 hour prior to carrageenan injection. A volume of $0.05 \mathrm{~mL}$ of $1 \%$ carrageenan in sterile normal saline solution (NSS) was injected intradermally into the plantar side of the right hind paw of rat. The edema volumes were determined using a plethysmometer (model 7140, Ugo Basile, Italy) before and 1,3 , and $5 \mathrm{~h}$ after carrageenan injection.
2.4.3. Cotton Pellet-Induced Granuloma Formation in Rats [16]. Male rats of weight range $200-250 \mathrm{~g}$ were chosen in this experiment. Two sterilized cotton pellets $(20 \pm$ $1 \mathrm{mg}$ ) were implanted subcutaneously; one on each side of the abdomen under thiopental anesthesia. The PI or PC extract $(1,200 \mathrm{mg} / \mathrm{kg})$, aspirin $(300 \mathrm{mg} / \mathrm{kg})$, and prednisolone $(5 \mathrm{mg} / \mathrm{kg})$ were orally administered once daily in a dosage regimen for 7 days, whereas the control group received 5\% Tween only. On the 8th day after implantation, rats were anaesthetized with thiopental sodium $(50 \mathrm{mg} / \mathrm{kg}$, intraperitoneally). Both cotton pellets and thymus were dissected, dried at $60^{\circ} \mathrm{C}$ for $18 \mathrm{~h}$ and their dry weight determined. Change in body weight from the beginning and the end of experiment was also recorded. The transudative and granuloma weights were calculated as well as percent granuloma inhibition of the test drugs.

\subsection{Analgesic Study}

2.5.1. Formalin Test in Mice [17]. Male ICR mice weighing $30-40 \mathrm{~g}$ were divided into six groups of six animals each. Control group received 5\% Tween 80 . Aspirin $(300 \mathrm{mg} / \mathrm{kg})$ and morphine $(10 \mathrm{mg} / \mathrm{kg})$ were used as a reference group. PI and PC extract were administered at the doses of 300, 600, and $1,200 \mathrm{mg} / \mathrm{kg}$. The formalin test consists of two distinctive phases. For the early phase assessment, test substances were orally administered to male ICR mice $1 \mathrm{~h}$, whereas morphine was injected intraperitoneally $30 \mathrm{~min}$ before the formalin injection. Twenty $\mu \mathrm{L}$ of $1 \%$ formalin in NSS was injected subcutaneously into the left dorsal hind paw. Time mice spent on licking of the injected hind paw was determined between $0-5 \mathrm{~min}$ after the formalin injection. In the late phase, formalin was injected after oral administration of test substances for $40 \mathrm{~min}$, or morphine injection for $10 \mathrm{~min}$. Next, the licking time was determined between 20 and $30 \mathrm{~min}$ after the formalin injection.

\subsection{Antipyretic Study}

2.6.1. Yeast-Induced Hyperthermia in Rats [18]. Before inducing pyrexia, the initial rectal temperature of male rats weighing 200-250 g was recorded using a twelve-channel electric thermometer (LETICA, model TMP 812 RS, Panlab S.L., Spain). Next, hyperthermia was induced by subcutaneous injection of $1 \mathrm{~mL} / 100 \mathrm{~g}$ body weight of $25 \%$ yeast in NSS. The rectal temperatures were recorded $18 \mathrm{~h}$ later. Then, those animals which show a rise in rectal temperature of more than $1^{\circ} \mathrm{C}$ were orally administered with test substances; PI and PC extracts were $(300,600,1,200 \mathrm{mg} / \mathrm{kg})$, aspirin $(300 \mathrm{mg} / \mathrm{kg}$ ), and $5 \%$ Tween 80 (control group). The rectal temperature of animals was recorded every $30 \mathrm{~min}$ for $2 \mathrm{~h}$ following the treatment.

2.7. Statistical Analysis. Results were expressed as mean \pm standard error of mean (S.E.M.). Statistical significance was determined by one-way analysis of variance (ANOVA) and post hoc least-significant difference (LSD) test using SPSS software (version 11.0). The $P$ values less than 0.05 were considered significant. 


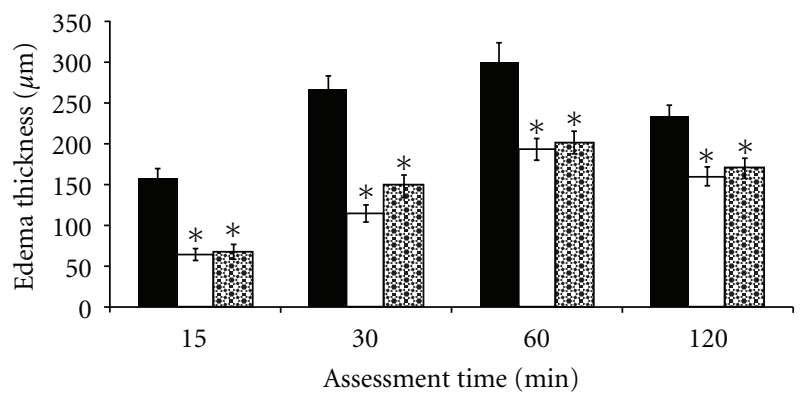

(a)

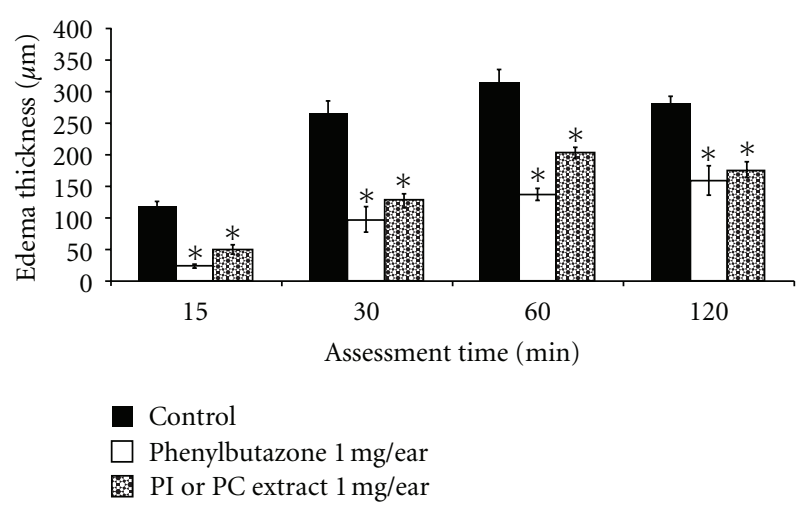

(b)

Figure 1: Effects of PI extract (a) and PC extract (b) on EPPinduced ear edema formation in rats. ${ }^{*}$ Significantly different from the control group, $P<0.05$.

\section{Results}

3.1. Anti-Inflammatory Activities of Piper interruptum Opiz. and Piper chaba Linn. The EPP-induced rat ear edema is suitably a common model for screening and estimating antiinflammatory activity of test substances. Topical application of EPP on rat ears produced a marked edema formation as shown in Figure 1. PI and PC extract at the dose of $1 \mathrm{mg} /$ ear significantly inhibited the ear edema formation. As a positive control, phenylbutazone $(1 \mathrm{mg} / \mathrm{ear})$ exhibited significant inhibitory activity on the ear edema formation at all determination times.

Next, we used the carrageenan-induced paw edema model to further confirm the activities of the extracts. As depicted in Figure 2, PI extract, at doses of 300, 600, and $1,200 \mathrm{mg} / \mathrm{kg}$ reduced the paw edema at 1,3 , and $5 \mathrm{~h}$ after carrageenan injection. Similarly, PC extract, at doses of $1,200 \mathrm{mg} / \mathrm{kg}$ significantly reduced the paw edema at 3 and $5 \mathrm{~h}$ after carrageenan injection. The positive control aspirin $(300 \mathrm{mg} / \mathrm{kg}$ ) markedly produced significant inhibitory effect of the paw edema at all assessment times.

The cotton pellet-induced granuloma formation in rats was further conducted to determine whether the extracts are able to inhibit the chronic inflammation. The positive control group treated with prednisolone $(5 \mathrm{mg} / \mathrm{kg}$, p.o.), daily for 7 days elicited a noticeable inhibition on transudation and granuloma formation (Table 1). In contrast,

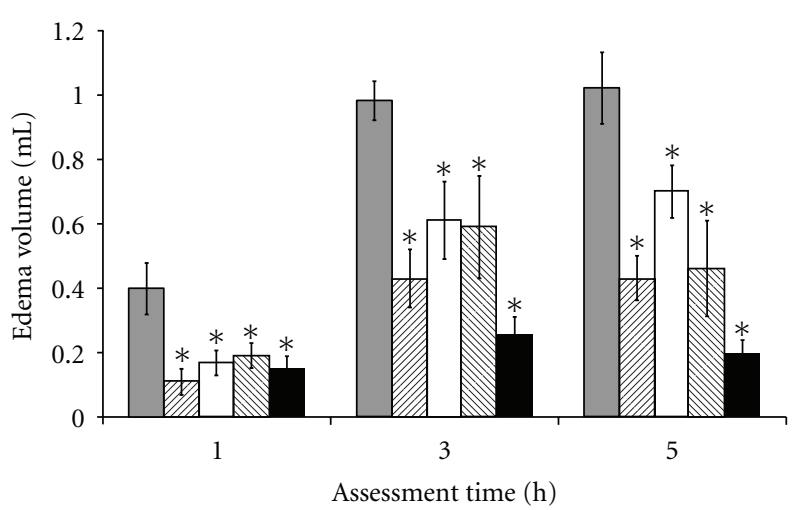

(a)

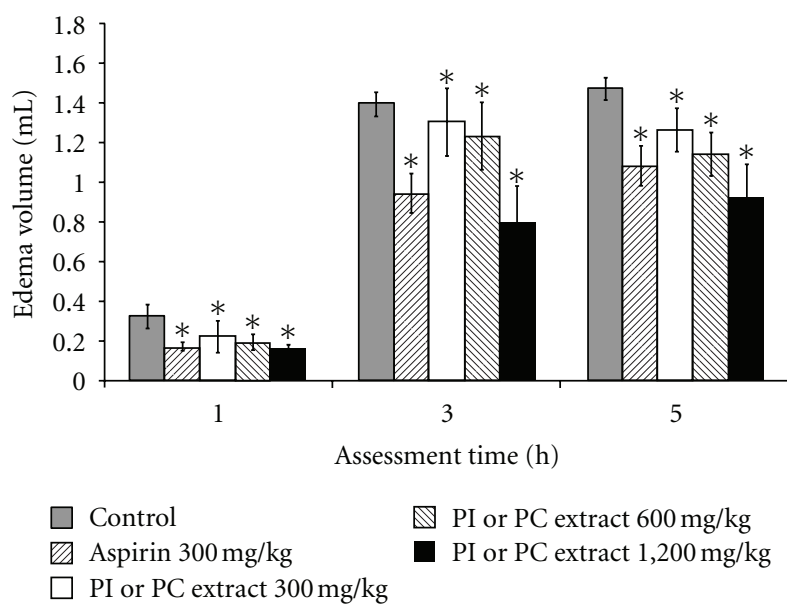

(b)

Figure 2: Effects of PI extract (a) and PC extract (b) on carrageenan-induced paw edema in rats. ${ }^{*}$ Significantly different from the control group, $P<0.05$.

aspirin $(300 \mathrm{mg} / \mathrm{kg})$ did not reduce both parameters. PI extract at the dose of $1,200 \mathrm{mg} / \mathrm{kg}$ decreased transudative weight, whereas PC extract reduced both transudative and granuloma weights. In addition, PI and PC extracts, similar to prednisolone, significantly decreased the body weight gain and thymus weight of animals while aspirin did not affect those parameters (Table 2).

3.2. Analgesic and Antipyretic Activities of Piper interruptum Opiz. and Piper chaba Linn. The formalin test is an applicable and reliable model of nociception. As shown in Figure 3, all doses of PI and PC extracts, aspirin, and morphine elicited significant inhibitory effect on the formalin test in mice. Significantly, the PI extract had a much smaller effect in the early phase than the other treatments.

In the antipyretic study, PI extract at doses of 300, $600,1,200 \mathrm{mg} / \mathrm{kg}$ and aspirin significantly decreased the rectal temperature of hyperthermia rats at all recorded times (Figure 4(a)). Likewise, PC extract at the doses of 600 and $1,200 \mathrm{mg} / \mathrm{kg}$ significantly reduced the rectal temperature of rats as shown in Figure 4(b). 
TABLE 1: Effects of PI and PC extracts on granuloma formation and transudation in cotton pellet-induced granuloma formation in rats.

\begin{tabular}{lccccc}
\hline & Dose $(\mathrm{mg} / \mathrm{kg})$ & $\begin{array}{c}\text { Granuloma wet } \\
\text { weight }(\mathrm{mg})\end{array}$ & $\begin{array}{c}\text { Granuloma dry } \\
\text { weight }(\mathrm{mg})\end{array}$ & $\begin{array}{c}\text { Transudative } \\
\text { weight }(\mathrm{mg})\end{array}$ & $\begin{array}{c}\text { Granuloma weight } \\
(\mathrm{mg} / \mathrm{mg} \text { cotton })\end{array}$ \\
\hline Control & - & $518.4 \pm 58.1$ & $91.0 \pm 8.2$ & $427.4 \pm 50.2$ & $3.5 \pm 0.4$ \\
Prednisolone & 5 & $289.9 \pm 10.8^{*}$ & $66.6 \pm 4.7^{*}$ & $223.3 \pm 8.6^{*}$ & $2.3 \pm 0.2^{*}$ \\
Aspirin & 300 & $473.9 \pm 25.7$ & $99.2 \pm 9.2$ & $374.7 \pm 22.6$ & $4.0 \pm 0.5$ \\
PI extract & 1,200 & $349.0 \pm 30.9^{*}$ & $86.4 \pm 9.1$ & $262.6 \pm 24.2^{*}$ & $3.3 \pm 0.4$ \\
PC extract & 1,200 & $253.9 \pm 15.3^{*}$ & $58.2 \pm 3.6^{*}$ & $196.7 \pm 13.0^{*}$ & $1.9 \pm 0.2^{*}$ \\
\hline
\end{tabular}

Data represent mean \pm S.E.M. $(n=6) . *$ Significantly different from the control group, $P<0.05$.

GI: granuloma inhibition $=($ Granuloma weight in test group $/$ Granuloma weight in control group $) \times 100$.

TABle 2: Effects of PI and PC extracts on body weight and thymus weight in cotton pellet-induced granuloma formation in rats.

\begin{tabular}{lccccc}
\hline & $\begin{array}{c}\text { Dose } \\
(\mathrm{mg} / \mathrm{kg})\end{array}$ & Initial & $\begin{array}{c}\text { Body weight }(\mathrm{g}) \\
\text { Final }\end{array}$ & Gain & $\begin{array}{c}\text { Dry thymus weight } \\
(\mathrm{mg} / 100 \mathrm{~g})\end{array}$ \\
\hline Control & - & $384.2 \pm 20.5$ & $392.5 \pm 20.1$ & $8.3 \pm 2.5$ & $22.2 \pm 1.4$ \\
Prednisolone & 5 & $384.2 \pm 20.9$ & $367.5 \pm 13.3$ & $-16.7 \pm 10.8^{*}$ & $17.8 \pm 0.7^{*}$ \\
Aspirin & 300 & $406.7 \pm 15.7$ & $399.2 \pm 13.6$ & $-7.5 \pm 2.8$ & $20.0 \pm 1.0$ \\
PI extract & 1,200 & $373.3 \pm 9.4$ & $356.7 \pm 9.4^{*}$ & $-16.6 \pm 6.7^{*}$ & $15.2 \pm 0.7^{*}$ \\
PC extract & 1,200 & $384.2 \pm 9.9$ & $339.2 \pm 13.5^{*}$ & $-45.0 \pm 5.3^{*}$ & $12.6 \pm 1.4^{*}$ \\
\hline
\end{tabular}

Data represent mean \pm S.E.M. $(n=6) . *$ Significantly different from the control group, $P<0.05$.

\section{Discussion}

Results of the present study reveal that ethanolic extracts of Piper interruptum Opiz. and Piper chaba Linn. possesses antiinflammatory, analgesic, and antipyretic activities in animal models.

During the acute phase of inflammation, key inflammatory mediators including histamine, serotonin, bradykinin, and prostaglandin are released in order to promote vasodilatation and vascular permeability as well as edema [19]. In the present study, PI and PC extracts showed the inhibitory effect on the ear edema formation induced by EPP. This result suggested that PI and PC extracts possessed anti-inflammatory activity by blocking the inflammatory mediators of the acute phase of inflammation.

The carrageenan-induced paw edema is considered as a model of the acute phase of inflammation which is widely used for discovery and investigation of anti-inflammatory drug [15]. Especially, this model is known to be sensitive to cyclooxygenase inhibitors and has been used to evaluate the effect of NSAIDs, which involves the inhibition of PGs synthesis [20]. Paw edema is processed by several inflammatory mediator released in ordinate sequence. The initial phase is caused by the release of histamine, serotonin, and bradykinin and followed by the release of prostaglandins (PGs) at the 3rd hour and lasts for about 6 hour after carrageenan injection [20]. The final phase appears to be most interesting in which the maximal vascular response occurs with the leukocyte migration to the inflamed area [21]. In the present study, oral administration of PI or PC extract suppressed the hind paw edema. The significant inhibitory effect of both extracts on carrageenan-induced paw edema at the 3rd hour suggests that the underlying mechanism of action of PI and PC extracts may involve blocking of the PGs synthesis and/or the other inflammatory mediators.

Cotton pellet-induced granulation is commonly used to assess the transudative and proliferative components of chronic inflammation. The subcutaneous implantation of cotton pellet in rat has been divided into at least three response phases, transudative phase, exudative phase, and proliferative phase. The transudative phase is defined as the increase in wet weight of the pellet that occurs during first 3 hour. An exudative phase is defined as plasma leaking from bloodstream around the granuloma that occurs between 3 and 72 hour after the implantation of pellet. The proliferative phase is measured as the increase in dry weight of the granuloma that occurs between 3 and 6 days after the implantation [16]. In addition, the implanted material induces a host inflammatory response and modulates the release of inflammatory mediators which finally lead to tissue proliferation and granular formation [22-24]. NSAIDs such as aspirin elicit a slight inhibition, whereas steroidal antiinflammation drugs strongly inhibit both transudative and proliferative phase of inflammation [16]. In this study, similar to prednisolone, PI and PC extract showed similar effects on both transudative and proliferative phases and reduced the body weight gain as well as the thymus weight. The results obtained suggest a mechanism of anti-inflammatory activity of PI and PC extract as steroidal-like effect.

The formalin test elucidates central and peripheral activities of nociception. The response pattern has two distinct periods of intensive licking activity, an early response (0$5 \mathrm{~min}$ after injection) and a late response (20-30 min after injection). The early phase is due to direct effect of formalin 


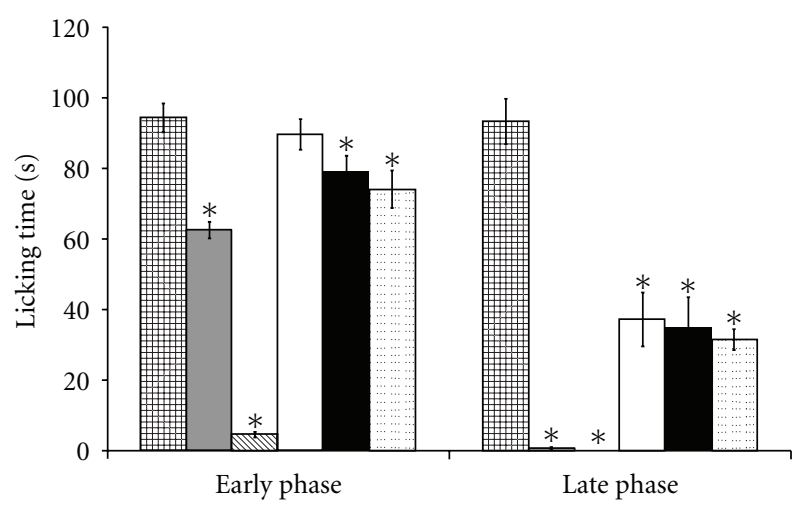

(a)

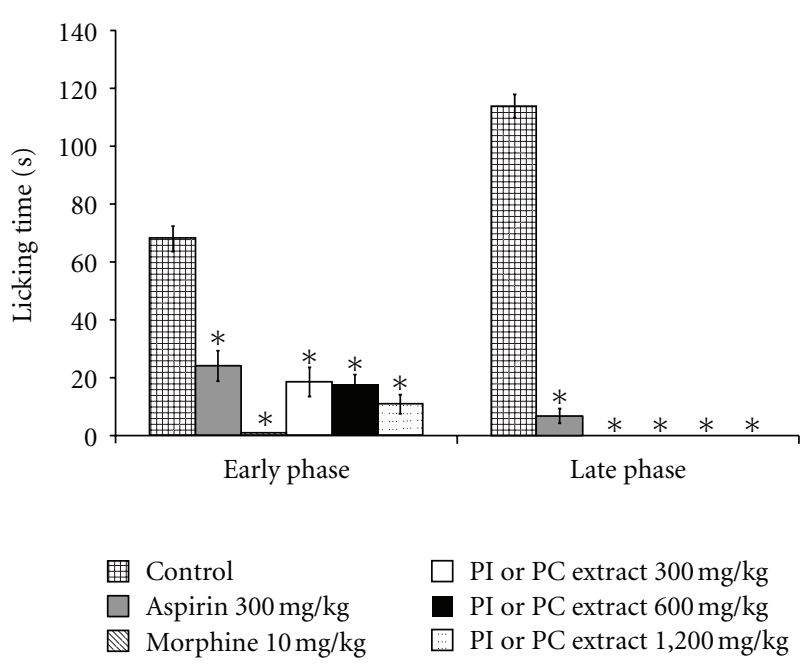

(b)

FIGURE 3: Effects of PI extract (a) and PC extract (b) on formalin test in mice. ${ }^{*}$ Significantly different from the control group, $P<$ 0.05 .

on nociceptors (noninflammatory pain). The late phase response is development of an inflammatory response and release of analgesic mediators, which reflect inflammatory pain [17]. Experimental results have indicated that substance $\mathrm{P}$ and bradykinin participate in the early phase, whereas histamine, serotonin, bradykinin, and PGs are involved in the late phase [25]. Our study showed analgesic activity of PI and PC extracts on both phases of the formalin test suggesting both direct analgesic effects on the nociceptor and an inhibition of inflammatory pain. Thus, their mode of action possibly involves the synthesis and/or release of PGs and/or other pain mediators.

Fever is provoked by many exogenous substances in animal models, including bacterial endotoxins and microbe infection. Exogenous pyrogen induces the production of proinflammatory cytokines, such as interleukin- $1 \beta$ (IL-1 $\beta$ ), IL6 , interferon- $\alpha$ (IFN- $\alpha$ ), and tumor necrosis factor- $\alpha$ (TNF$\alpha$ ), which enter hypothalamic circulation and stimulate the release of local prostaglandins (PGs), thereby resetting the hypothalamic thermal setpoint [26]. Like aspirin, both PI

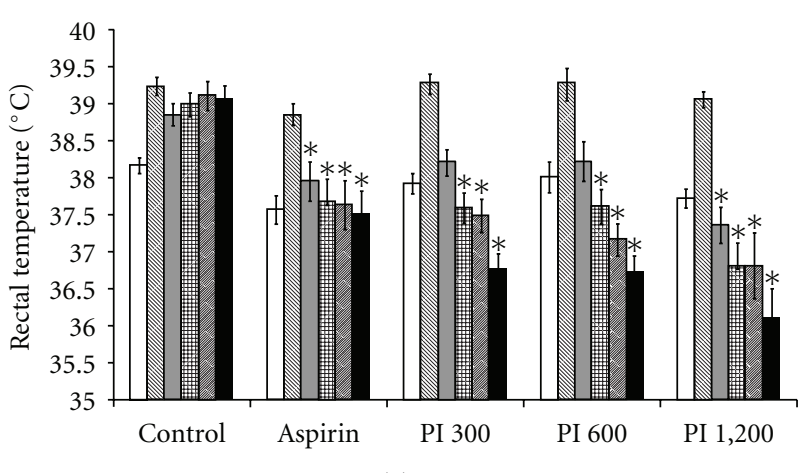

(a)

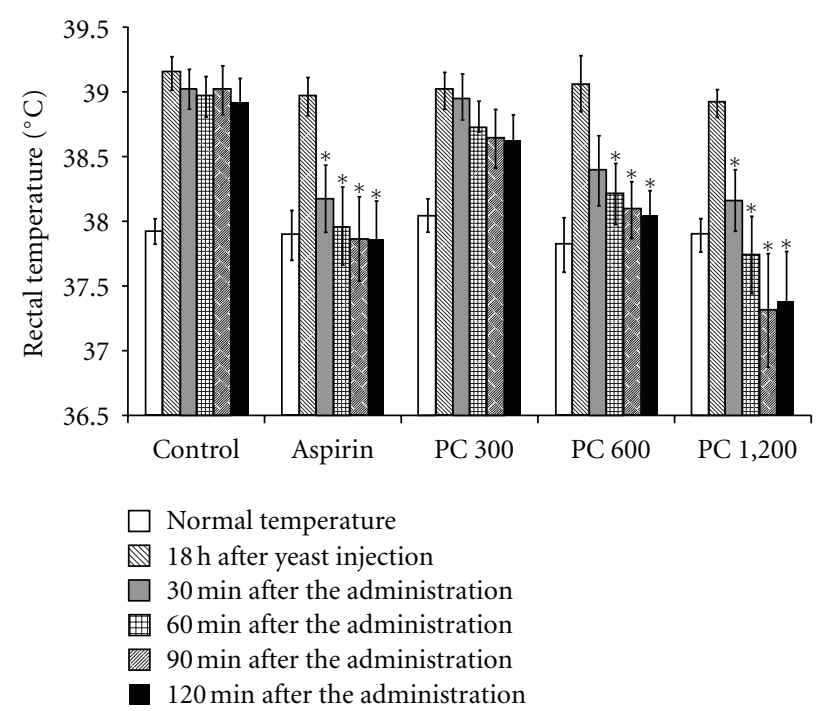

(b)

Figure 4: Effects of PI extract (a) and PC extract (b) on yeastinduced hyperthermia in rats. * Significantly different from the control group, $P<0.05$.

and PC extract showed antipyretic activity which is likely due to inhibition of the synthesis and/or release of local $\mathrm{PGE}_{2}$ into the preoptic area of anterior hypothalamus $[26,27]$.

\section{Conclusion}

The overall results demonstrate that extracts of Piper interruptum Opiz. and Piper chaba Linn. have anti-inflammatory, analgesic, and antipyretic activities in laboratory animals. The results obtained suggest their mechanism of action similar to NSAIDs as well as steroid-like effect. Nonetheless, the precise mechanism and the bioactive principles responsible for these actions remain to be elucidated.

\section{Acknowledgment}

This works were supported by the National Research University Project of Thailand Office of Higher Education Commission and Thammasat University Research Fund. 


\section{References}

[1] C. Pichiensunthon and V. Jeerawongs, Traditional Pharmacy Handbook, vol. 5, Ammarin Publisher, Bangkok, Thailand, 2004.

[2] U. Chaithong, W. Choochote, K. Kamsuk et al., "Larvicidal effect of pepper plants on Aedes aegypti (L.) (Diptera: Culicidae)," Journal of Vector Ecology, vol. 31, no. 1, pp. 138-144, 2006.

[3] K. Ingkaninan, P. Temkitthawon, K. Chuenchom, T. Yuyaem, and W. Thongnoi, "Screening for acetylcholinesterase inhibitory activity in plants used in Thai traditional rejuvenating and neurotonic remedies," Journal of Ethnopharmacology, vol. 89, no. 2-3, pp. 261-264, 2003.

[4] P. Saralamp, W. Chuakul, R. Temsiririrlkul, and T. Clayton, Medicinal Plant in Thailand, vol. 1, Department of Pharmaceutical Botany, Faculty of Pharmacy, Mahidol University, Pathom, Thailand, 1996.

[5] N. Singh, S. Kumar, P. Singh et al., "Piper longum Linn. Extract inhibits TNF- $\alpha$-induced expression of cell adhesion molecules by inhibiting NF- $\kappa \mathrm{B}$ activation and microsomal lipid peroxidation," Phytomedicine, vol. 15, no. 4, pp. 284-291, 2008.

[6] S. W. Lee, Y. K. Kim, K. Kim et al., "Alkamides from the fruits of Piper longum and Piper nigrum displaying potent cell adhesion inhibition," Bioorganic and Medicinal Chemistry Letters, vol. 18, no. 16, pp. 4544-4546, 2008.

[7] S. Kumar, V. Singhal, R. Roshan, A. Sharma, G. W. Rembhotkar, and B. Ghosh, "Piperine inhibits TNF- $\alpha$ induced adhesion of neutrophils to endothelial monolayer through suppression of NF- $\kappa \mathrm{B}$ and I $\kappa \mathrm{B}$ kinase activation," European Journal of Pharmacology, vol. 575, no. 1-3, pp. 177-186, 2007.

[8] H. Matsuda, K. Ninomiya, T. Morikawa, D. Yasuda, I. Yamaguchi, and M. Yoshikawa, "Protective effects of amide constituents from the fruit of Piper chaba on dgalactosamine/TNF- $\alpha$-induced cell death in mouse hepatocytes," Bioorganic and Medicinal Chemistry Letters, vol. 18, no. 6, pp. 2038-2042, 2008.

[9] E. S. Sunila and G. Kuttan, "Immunomodulatory and antitumor activity of Piper longum Linn. and piperine," Journal of Ethnopharmacology, vol. 90, no. 2-3, pp. 339-346, 2004.

[10] K. Selvendiran, J. Prince Vijeya Singh, and D. Sakthisekaran, "In vivo effect of piperine on serum and tissue glycoprotein levels in benzo(a)pyrene induced lung carcinogenesis in Swiss albino mice," Pulmonary Pharmacology and Therapeutics, vol. 19, no. 2, pp. 107-111, 2006.

[11] E. S. Sunila and G. Kuttan, "Piper longum inhibits VEGF and proinflammatory cytokines and tumor-induced angiogenesis in C57BL/6 mice," International Immunopharmacology, vol. 6, no. 5, pp. 733-741, 2006.

[12] P. Devan, S. Bani, K. A. Suri, N. K. Satti, and G. N. Qazi, "Immunomodulation exhibited by piperinic acid through suppression of proinflammatory cytokines," International Immunopharmacology, vol. 7, no. 7, pp. 889-899, 2007.

[13] H. Zhang, H. Matsuda, S. Nakamura, and M. Yoshikawa, "Effects of amide constituents from pepper on adipogenesis in 3T3-L1 cells," Bioorganic and Medicinal Chemistry Letters, vol. 18, no. 11, pp. 3272-3277, 2008.

[14] R. Brattsand, A. Thalen, and K. Roempke, "Influence of $16 \alpha$, $17 \alpha$-acetal substitution and steroid nucleus fluorination on the topical to systemic activity ratio of glucocorticoids," Journal of Steroid Biochemistry, vol. 16, no. 6, pp. 779-786, 1982.

[15] C. A. Winter, E. A. Risley, and G. W. Nuss, "Carrageenininduced edema in hind paw of the rat as an assay for antiiflammatory drugs," Proceedings of the Society for Experimental
Biology and Medicine. Society for Experimental Biology and Medicine, vol. 11, pp. 544-547, 1962.

[16] K. F. Swingle and F. E. Shideman, "Phases of the inflammatory response to subcutaneous implantation of a cotton pellet and their modification by certain anti-inflammatory agents," Journal of Pharmacology and Experimental Therapeutics, vol. 183, no. 1, pp. 226-234, 1972.

[17] S. Hunskaar and K. Hole, "The formalin test in mice: dissociation between inflammatory and non-inflammatory pain," Pain, vol. 30, no. 1, pp. 103-114, 1987.

[18] U. M. Teotino, L. P. Friz, A. Gandini, and D. Della Bella, "Thio derivatives of 2,3-dihydro-4H-1,3-benzoxazin-4-one. Synthesis and pharmacological properties," Journal of Medicinal Chemistry, vol. 6, no. 3, pp. 248-250, 1963.

[19] R. P. Carlson, L. O’Neill-Davis, J. Chang, and A. J. Lewis, "Modulation of mouse ear edema by cyclooxygenase and lipoxygenase inhibitors and other pharmacologic agents," Agents and Actions, vol. 17, no. 2, pp. 197-204, 1985.

[20] M. Di Rosa and D. A. Willoughby, "Screens for anti-inflammatory drugs," Journal of Pharmacy and Pharmacology, vol. 23, no. 4, pp. 297-298, 1971.

[21] R. Vinegar, W. Schreiber, and R. Hugo, "Biphasic development of carrageenin edema in rats," Journal of Pharmacology and Experimental Therapeutics, vol. 166, no. 1, pp. 96-103, 1969.

[22] A. Remes and D. F. Williams, "Immune response in biocompatibility," Biomaterials, vol. 13, no. 11, pp. 731-743, 1992.

[23] L. Tang and J. W. Eaton, "Inflammatory responses to biomaterials," American Journal of Clinical Pathology, vol. 103, no. 4, pp. 466-471, 1995.

[24] W. J. Hu, J. W. Eaton, and L. Tang, "Molecular basis of biomaterial-mediated foreign body reactions," Blood, vol. 98, no. 4, pp. 1231-1238, 2001.

[25] M. Shibata, T. Ohkubo, H. Takahashi, and R. Inoki, "Modified formalin test: characteristic biphasic pain response," Pain, vol. 38, no. 3, pp. 347-352, 1989.

[26] S. Dalal and D. S. Zhukovsky, "Pathophysiology and management of fever," Journal of Supportive Oncology, vol. 4, no. 1, pp. 9-16, 2006.

[27] S. Li, L. R. Ballou, S. G. Morham, and C. M. Blatteis, "Cyclooxygenase-2 mediates the febrile response of mice to interleukin1ß," Brain Research, vol. 910, no. 1-2, pp. 163-173, 2001. 

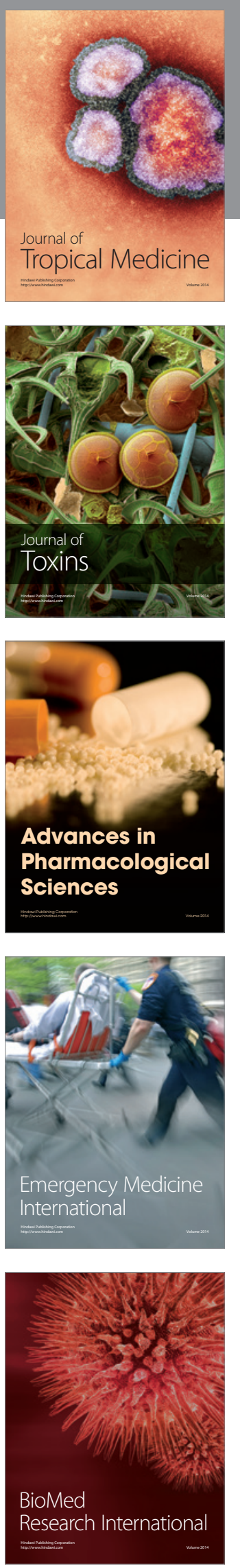
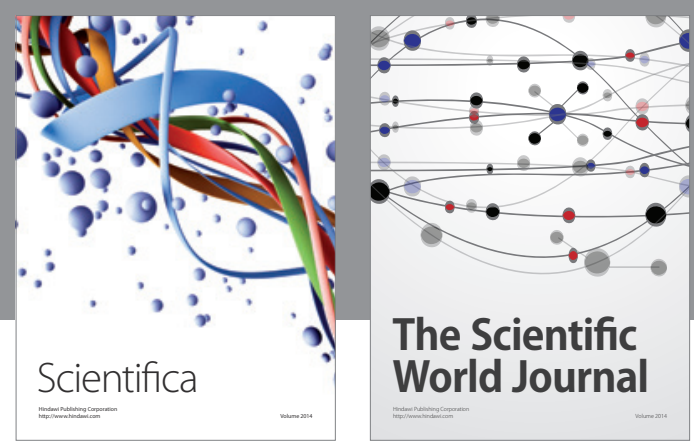

The Scientific World Journal
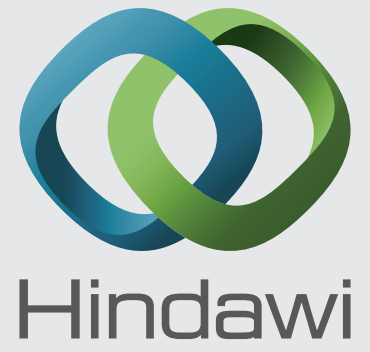

Submit your manuscripts at

http://www.hindawi.com
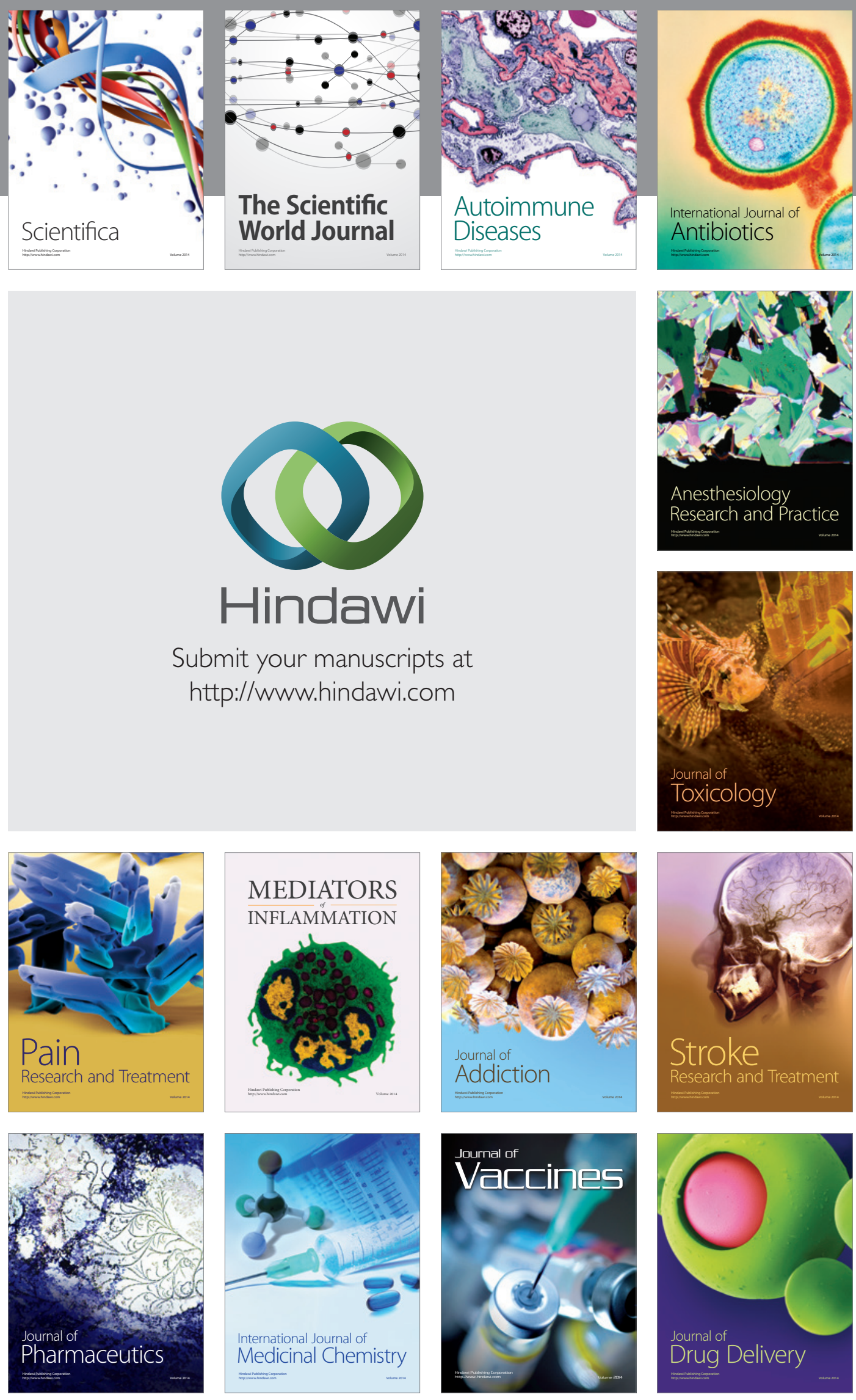